\title{
Meevik Formula - for Estimating the Mesiodistal Width of Permanent Mandibular Molar
}

\author{
Meenakshi M. Tiwari ${ }^{1}$, Vikrant V. Jadhav², Pallavi Daigavane ${ }^{3}$, Ranjit Kamble ${ }^{4}$ \\ 1, 2, 3,4 Department of Orthodontics and Dentofacial Orthopaedics Sharad Pawar \\ Dental College and Hospital, Sawangi, Wardha, Maharashtra, India.
}

\section{ABSTRACT}

\section{BACKGROUND}

The mandibular first molar is important from orthodontic perspective in relation to its utility as an anchor tooth, strongest tooth, $1^{\text {st }}$ permanent tooth to erupt in the arch, frequently most common tooth to get affected by caries or being extracted. So it is important to know the dimension of permanent mandibular first molar.

\section{METHODS}

300 dental casts of individuals with class I malocclusion having age range from 18 30 years were evaluated using digital caliper.

\section{RESULTS}

Mean values tabulated mandibular molars were 0.65 and 0.92 as min. and max. values respectively. Mean standard error (MSE) was tabulated as 0.005 and 0.006 on left and right side respectively. Standard deviation (SD) was observed as 0.081 and MeeVik formula for calculating the mesiodistal dimension of permanent first molar was derived.

\section{CONCLUSIONS}

Missing molars are frequently addressed. In these scenarios, the decision of replacing or protracting $2^{\text {nd }}$ molars in the space of missing $1^{\text {st }}$ molars becomes essential. For this, measuring mesiodistal width of $1^{\text {st }}$ molar becomes important for achieving proper occlusion. MeeVik formula will benefit the patients reporting for orthodontic treatment.

\section{KEY WORDS}

Mandibular Molar, Missing Molar, Mesiodistal Width
Corresponding Author: Dr. Meenakshi Tiwari,

Junior Resident,

Department of Orthodontics and Dentofacial Orthopaedics, Sharad Pawar Dental College and Hospital, Sawangi, Wardha, Maharashtra, India. E-mail: drmeenakshigaud@gmail.com

DOI: $10.14260 /$ jemds/2021/75

How to Cite This Article:

Tiwari MM, Jadhav VV, Daigavane P, et al. Meevik formula - for estimating the mesiodistal width of permanent mandibular molar. J Evolution Med Dent Sci 2021;10(06):333-337, DOI: $10.14260 / j e m d s / 2021 / 75$

Submission 02-05-2020,

Peer Review 09-11-2020,

Acceptance 16-11-2020,

Published 08-02-2021.

Copyright (C) 2021 JEMDS. This is an open access article distributed under Creative Commons Attribution License [Attribution 4.0 International (CC BY 4.0)] 


\section{BACKGROUND}

Teeth particularly permanent mandibular first molars are affected with caries and often missing. According to Bhardwaj $\mathrm{V}$ et al. ${ }^{1}$ mandibular molars were significantly affected with caries. Macek et al. ${ }^{2}$ described that the permanent mandibular molars of both the sides were the utmost affected with caries in the oral cavity. It was witnessed that permanent mandibular molars are susceptible to caries than incisors, cuspids and bicuspids in all age groups and gender. Therefore, till the age of 18 years, most molars are carious which require restoration and replacement or are on the verge of extraction or have already been extracted. Permanent mandibular molar emerges at age of $6-7$ years. The operating orthodontist must do an accurate examination of the probable aspects accountable for its situation (missing / extracted / carious / impacted) and formulate the finest therapeutic strategy for correcting the situation. These conditions are well addressed from the period of mixed dentition. But, problem arises when the condition occurs in permanent dentition. There are no such guidelines for assessing width of molar for both the dentition. The condition becomes complicated and determining as to get a second molar into its correct position with the help of orthodontics or to substitute it with the help of prosthesis or with an embedded screw. Formulating a treatment plan in case of patients with tooth missing and moreover there is an issue regarding their prior records. For correcting these difficulties, MeeVik formula is used for measuring mesiodistal dimension of mandibular molar is beached on the collective dimension of permanent mandibular central and lateral incisors is calculated and the formula is applied to get the dimension of molar.

Permanent $1^{\text {st }}$ molar removal is basically completed only if molar is grossly carious or not possible to restore it. The theory of extraction or removal of permanent mandibular molar contributes to anterior open bite closure as fulcrum in the posterior region is removed and it has been described that this pattern of removal of teeth preserves or somewhat decreases the vertical skeletal malrelationships ${ }^{3}$. Therefore, the mesiodistal dimension of permanent mandibular first molar of both the sides is essential to distinguish. But, in the maximum number of cases, the $2^{\text {nd }}$ permanent mandibular molar substitutes the $1^{\text {st }}$ permanent mandibular molar. Moreover, the anterior open bite remains the same. As the $2^{\text {nd }}$ permanent molar is mesially moved into the extraction space, extrusion of the distal part is typically observed due to improper procedure, thus aggregating or preserving the anterior open bite. Therefore, it is significant to determine the mesiodistal dimensions of permanent mandibular $1^{\text {st }}$ molar. Generally, if removal of this tooth is to be done, space closing mechanism is the determining aspect in the accomplishment of the overbite improvement. 4

This case management substitute would be of utmost important if appropriate timing is given preference. Kuhlberg in 2003 described that if the $2^{\text {nd }}$ permanent molars have not appeared and if the individual is only biting on the $1^{\text {st }}$ permanent molars, removal of the $1^{\text {st }}$ molars would exclude the augmented vertical dimensions and the $2^{\text {nd }}$ molars would only be able to appear up to the new established vertical height.

The permanent $1^{\text {st }}$ molars are enormously crucial in aspect of normal occlusion. Though, in few cases of malocclusion, removal of permanent $1^{\text {st }}$ permanent molars is given preference over other teeth in the arch. In a procedure to remove the $1^{\text {st }}$ permanent molars of the arch in planned orthodontic treatment method for the patient, there lies definite objective indications for $1^{\text {st }}$ permanent molar removal; these contain widespread carious area over tooth surface, outsized fillings or restorations, endodontically treated or have periodontal lesions or weak periodontal condition, or are completely hypoplastic teeth. ${ }^{5}$

Removal of $1^{\text {st }}$ permanent molars of both the arch, particularly teeth with doubtful long-lasting prognosis, could improvise on retaining extra fit teeth, gaining adequate orthodontic outcomes and improve stability of occlusion after treatment. Removal of a grossly decayed $1^{\text {st }}$ permanent molar is performed only in conditions wherein $2^{\text {nd }}$ and $3^{\text {rd }}$ permanent molars are in good state and form and the $2^{\text {nd }}$ permanent molar of both the side can be managed orthodontically to take the spot of the $1^{\text {st }}$ permanent molar.

The $1^{\text {st }}$ permanent molar is an imperative buttress location in an edentulous maxillary arch in the oral cavity. The biting pressure in this area upsurges to $200 \mathrm{lbs}$. associated with 1 / 2 of this quantity in the bicuspid area. As a significance, the $1^{\text {st }}$ permanent molar is tooth area is twice as large as bicuspid on both sides of the arch. Moreover, the bone density in the maxillary molar area is frequently inferior to the bicuspid area of the arch. As a consequence, superior width miniscrew or multiple miniscrews are recommended and no cantilevered force should be applied in the permanent molar area. ${ }^{6}$

First molars are missing in one-third of the cases, the second molars in almost all the cases and the wisdom teeth are always missing. For those patients, the implant step in the posterior mandible is tricky. Transversal relationships are frequently inverted, bone thickness is reduced and the implant height is insufficient, because, even if the vertical dimension is weakly affected, the problem is the location of the inferior alveolar nerve. In this case, we have to study the compatibility between prosthetic and bone height in order to plan the most adapted surgical approach; the only graft or the inferior alveolar nerve derivation. So, when the prosthetic height is reduced, we do prefer the nerve lateralisation in order to utilize all the mandibular height for implants. When the prosthetic height is too important or cannot be reduced, we prefer the onlay graft in order to increase bone height and reduce the crown / root ratio. Bone graft also permits the correction of part of the transversal discrepancies in the case of tooth agenesis.

The 1st permanent mandibular molars of both the sides i.e. right and left are the first permanent teeth to appear in the arch and frequently perform a fundamental part in the preservation of the dental arch form and suitable occlusal structures. Therefore, 1st permanent mandibular molars are frequently the 1 st teeth to be carious and grownup cases repeatedly have had one or more teeth restored to maintain the proper tooth structure and substitute the preceding outsized restorations. Permanency data of crowns have produced very dissimilar outcomes, with the average life span which was described to be 10.3 years. The principal reason of improper or failed crown is endodontic therapy. Therefore, 1 st permanent mandibular molars teeth are at a greater risk for removal as an outcome of these difficulties and associated with 
decay, as these impediments are a primary reason of single posterior tooth extraction in patients. ${ }^{7}$

\section{METHODS}

The observational study was approved by the institutional ethical committee (Ref No. - DMIMS (DU) / IEC / 2018-19 / 7151). Patients who fulfilled the inclusion criteria were selected for the study. Informed consent was obtained from patients before stating the study.

\section{Inclusion Criteria}

- Patients having full permanent set of teeth.

- $\quad$ Patients with age group between 18 - 30 years of age.

- Patients which have molar and canine relation as Class I.

\section{Exclusion Criteria}

- Patients with missing, un-erupted and restored teeth.

- Patients with coronal coverage, attrition and deformed teeth.

Sample size was taken as per the convenience of the study. 300 patients were selected for the study. For this, perfect impression of maxillary and mandibular arches were done. For this Putty impression material was used. After this, to avoid impression distortion, recorded impression were poured instantaneously. This was done with dental stone. After setting of dental stone, the cast were retrieved and trimmed accordingly. Bases were then made. Dimension in mesiodistal aspect were then recoded. For deriving MeeVik formula, permanent mandibular central and lateral incisor is used. Through different permutation and combination procedure, MeeVik formula was derived.

\section{Statistical Analysis}

Statistical analysis was done to calculate mean, average difference, coefficient of variance and standard error.

\section{Methods}

For measurement of mesiodistal dimension on dental model, a modified digital vernier caliper was used. The tips or points of the digital vernier caliper which are used for measurement on the model were modified by trimming to adjust easily in the contact points of the teeth for accurate measurement. The tips or points of the modified digital vernier caliper was placed in the preferred region of the tooth and the mesiodistal width of the tooth was measured and charted into the table shown below. All the readings were done in millimeters. The reading were calculated and tabulated in the following table - (Table 1).

\begin{tabular}{|cccccccccccccccc|}
\hline UR & 7 & 6 & 5 & 4 & 3 & 2 & 1 & 1 & 2 & 3 & 4 & 5 & 6 & 7 & UL \\
LR & 7 & 6 & 5 & 4 & 3 & 2 & 1 & 1 & 2 & 3 & 4 & 5 & 6 & 7 & LL \\
\hline \multicolumn{11}{|c|}{ Table 1. Chart for Entry of Mesiodistal Width of Teeth } \\
\hline
\end{tabular}

The mesiodistal width of mandibular molar, lateral and central incisors on right and left sides were calculated and tabulated using modified digital vernier caliper on study models of 300 patients. The mean and the SD of the measured dimension was evaluated. The amount between the dimensions of the mandibular molars was assessed using mandibular incisors (central and lateral) and a new innovative MeeVik formula was derived. ${ }^{3}$

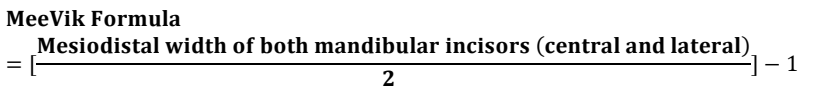

\section{RESULTS}

When this formula was checked in our Population we obtained following Results. Firstly, mean was calculated. Mean was calculated with permanent both mandibular incisors was with lower value of 0.65 and higher value of 0.92 . After this, mean standard error (MSE) was derived for both the sides. This value was 0.005 and 0.006 on left side and right side respectively. Standard deviation (SD) of 0.081 is observed. Average difference (error) of 0.06 and 0.06 for both sides respectively. Co-efficient of variance (COV) was observed to be 0.04 for both the sides. Based on obtained results, correct MeeVik formula was determined for our population. For MeeVik formula, mesiodistal dimensions of permanent mandibular molar is determined by using mesiodistal dimensions of lower incisors. Average difference which was observed is same on both, right and left side of the arch. The average difference was insignificant. For further accuracy of results \pm 0.5 is required.

\section{DISCUSSION}

There are various ways to measure the dimension of absent teeth. Tonn's ${ }^{3}$ formulated a technique to assess the dimension of absent permanent maxillary lateral incisor. This technique involves the mesiodistal dimension of all erupted incisors of both the arch. This formula is used to calculate the mesiodistal dimension of absent permanent maxillary lateral incisor. Therefore, this formula is not practical if any teeth were absent. It was also taking longer time. Moreover, Tonn's formula included sample from Caucasian population. Therefore, several authors examined its application in Indian scenario. When the Tonn's method was examined in Indian population, imprecise outcomes were acquired. So, it was important to devise the "MeeVik formula". This MeeVik formula is not difficult to apply in any situation, easy to recall and does not include all incisors for measurement.

The beneficiaries of these formulas are individuals in quest of aesthetic improvement for replacing missing permanent molars of both the arch. The MeeVik formula can also be used in patients which need aesthetic alteration of deformed permanent canine of both the arches. This MeeVik formula could be applied to all the aspects of dentistry.

The occurrence of congenital non-appearance or missing mandibular first molar is moderate but the incidence of carious molars is much high as it is the $1^{\text {st }}$ permanent tooth to appear in the individual around 6 years of age. ${ }^{4}$ Molars help in 
achieving the balance occlusion as the cusp to fossa relation is achieved, it also act as vertical stop preventing the supraeruption of antagonist molar in cases of missing molars in the antagonist arch. So, locating correct mesiodistal width of molar becomes important to achieve balance and harmony of the occlusion. This is the zone of apprehension for orthodontist in specific and dentist in common. ${ }^{5}$ Also in cases where in mandibular first molar are absent the protraction of second and third molar is quiet difficult due to dense cortical bone in mandible. Almost, all the orthodontists struggle to assess the correct mesiodistal width of molars so correct cusp fossa relation is not achieved leading to disturbed occlusion which can created disharmony amongst the dentoalveolar and TMJ. Till date mesiodistal width of molars was assessed on radiographs. But magnification errors and radiation exposure have questioned the accuracy of the radiographic method. ${ }^{8}$ Relying on radiographic methods, orthodontist have failed to achieve correct results. So, there was a need to precisely plan a formula to evaluate mesiodistal width of molars in both the arch. Therefore, we came up with the MeeVik formula which will solve the problem and improve accuracy regarding treatment planning on dental cast.

The MeeVik formula was formed by calculating the patient study models poured in dental stone of 300 patients. The mesiodistal dimension of the permanent mandibular molars and incisors of both the sides were calculated with the help of modified digital vernier calliper and then was charted. The mean and SD for MeeVik formula were analysed. Based on the theory of proportions, the formula for calculating dimensions of the mandibular permanent molars was based on the combined width of mandibular incisors. The MeeVik formula which was measured showed very negligible errors for our population which shows us that this formula is very well formulated to benefit individuals of our population. Average difference among the calculated and assumed standards of mandibular permanent left molars was $0.06 \mathrm{~mm}$ when both the mandibular incisors were used. For the mandibular permanent right molar the error was $0.06 \mathrm{~mm}$. Similarly, error of $0.07 \mathrm{~mm}$ was observed when both the mandibular incisors were used to predict the widths of the left mandibular molar. Similarly, for mandibular right molar error was of $0.08 \mathrm{~mm}$. Moreover, the dissimilarity was in the $2^{\text {nd }}$ decimal place. This was seen when the permanent mandibular incisors were used for predicting mesiodistal width of mandibular molar. This error or difference indicated the accuracy of the MeeVik formula to predict the results. This is new innovative formula. ${ }^{9}$ -13. The Formula that we propose is as follows -

MeeVik Formula for Missing Mandibular Molar (new formula)

MeeVik Formula

$=\left[\frac{\text { Mesiodistal width of both mandibular incisors (central and lateral) }}{2}\right]-1$

\section{CONCLUSIONS}

Missing molars are frequently observed in clinical practice. ${ }^{9}$ This condition is observed in individuals who are undergoing orthodontic treatment. The individuals mainly of age 18 - 30 years pursue orthodontic treatment. They have the problem of erupting of $3^{\text {rd }}$ molars also. In these scenarios, the decision of replacing or protracting $2^{\text {nd }}$ molars in the space of missing $1^{\text {st }}$ molars becomes essential. For this, measuring mesiodistal width of $1^{\text {st }}$ molar becomes important for achieving proper occlusion. MeeVik formula will benefit the patients reporting for orthodontic treatment.

Data sharing statement provided by the authors is available with the full text of this article at jemds.com.

Financial or other competing interests: None.

Disclosure forms provided by the authors are available with the full text of this article at jemds.com.

\section{REFERENCES}

[1] Bhardwaj VK, Kaundals JR, Chug A, et al. Rare occurrence of bilaterally impacted mandibular supernumerary teeth. Dental Hypotheses 2012;3(2):83-5.

[2] Macek MD, Mitola DJ. Exploring the association between overweight and dental caries among US children. Pediatric Dentistry 2006;28(4):375-80.

[3] Tonn P. Uber die mesio - distalen Zahn breiten relationen der Zahne des oberkiefers zudenents prechenden des unter kiefersbei normalen and anormalen occlusion. Diss, Berlin 1937.

[4] Leroy R, Bogaerts K, Lesaffre E, et al. Effect of caries experience in primary molars on cavity formation in the adjacent permanent first molar. Caries Research 2005;39(5):342-9.

[5] Lundstrom A. Intermaxillary tooth width ratio and tooth alignment and occlusion. Acta Odontol Scand 1955;12(34):265-92.

[6] Zachrisson BU. Improving orthodontic results in cases with maxillary incisors missing. American Journal of Orthodontics 1978;73(3):274-89.

[7] Thote AM, Uddanwadiker RV, Sharma K, et al. Optimum force system for intrusion and extrusion of maxillary central incisor in labial and lingual orthodontics. Computers in Biology and Medicine 2016;69:112-9.

[8] Baliga SM. Child oral health - care literacy in India: Can access to services be improved? Journal of the Indian Society of Pedodontics and Preventive Dentistry 2019;37(1):1-2.

[9] Baliga S. Emerging trends in pediatric dentistry. Journal of the Indian Society of Pedodontics and Preventive Dentistry 2018;36(2):107.

[10] Jadhav VV, Vasudevan SD, Kamble R, et al. ViVan Formula - a modified formula for estimating the mesiodistal width of maxillary central and lateral incisor. J Evolution Med Dent Sci 2020;9(14):1144-7.

[11] Tiwari MM, Jadhav VV, Kamble RH, et al. A review on evolution and controversies regarding surgical methods and timing of palatoplasty in UCLP cases. J Evolution Med Dent Sci 2020;9(4):236-44.

[12] Tiwari MM, Daigavane PS, Kamble R, et al. Establishment of cephalometric norms for UCLP cases from central india population falling under goslon 1 and 2 based on burstone analysis. J Evolution Med Dent Sci 2020;9(16):1365-8.

[13] Ghoshal PK, Kamble RH, Shrivastav SS, et al. Radiographic evaluation of alveolar bone dimensions in the inter radicular area between maxillary central incisors as "safe zone" for the placement of miniscrew implants in 
different growth patterns - a digital volume tomographical study. J Evolution Med Dent Sci 2019;8(51):3836-40. 